\title{
Reconstruction of the internal structure of the pore system of a complex dinosaur eggshell (Megaloolithus siruguei)
}

\author{
Diego RASSKIN-GUTMAN ${ }^{*}$, Javier ELEZ², Borja ESTEVE-ALTAVA ${ }^{1}$ \& Nieves LÓPEZ- \\ MARTÍNEZ ${ }^{2}$
}

${ }^{1}$ Theoretical Biology Research Group, Institute Cavanilles for Biodiversity and Evolutionary Biology, University of Valencia, Apdo. 22085, 46071 Valencia, Spain; diego.rasskin@uv.es; boresal@gmail.com

${ }^{2}$ Department of Paleontology, Faculty of Geology, Universidad Complutense de Madrid, 28040-Madrid, Spain; lopezmar@ geo.ucm.es; Javier.elez@geo.ucm.es

* Corresponding author

Rasskin-Gutman, D., Elez, J., Esteve-Altava, B. \& López-Martínez, N. 2013. Reconstruction of the internal structure of the pore system of a complex dinosaur eggshell (Megaloolithus siruguei). [Reconstrucción de la estructura interna del sistema de poros de una cáscara de huevo de dinosaurio compleja (Megaloolithus siruguei)]. Spanish Journal of Palaeontology, 28 (1), 61-68.

\section{ABSTRACT}

Despite the many reconstructions of fossil material that have recently appeared in the literature, dinosaur eggshells have never been reconstructed using computing techniques. Using the EMAC 3-D modelling methodology, we reconstruct a section of the Late Cretaceous Megaloolithus siruguei eggshell, which has a particularly complex pore system, exhibiting an intricate network of vertical, oblique, and horizontal pores.

Keywords: Dinosaur eggshell, 3-D reconstruction, palaeoclimate.

\section{RESUMEN}

A pesar de las numerosas reconstrucciones de material fósil que han aparecido recientemente en la literatura, las cáscaras de dinosaurio nunca han sido reconstruidas mediante el uso de técnicas de computación. Usando la metodología de modelización EMAC 3-D, reconstruimos una sección de la cáscara de huevo de Megaloolithus siruguei del Cretácico tardío, la cual tiene un sistema de poros particularmente complejo, exhibiendo una intrincada red de poros verticales, oblicuos y horizontales.

Palabras clave: Cáscara de huevo de dinosaurio, reconstrucción 3-D, paleoclima. 


\section{INTRODUCTION}

The amniotic egg is one of those structures that tell many tales about biological processes. Behind its overall shape the several forces that were in play during ovogenesis, from fertilization of the oocyte to egg deposition, can be deduced. This was already pointed out in D'Arcy Thompson's monumental work On Growth and Form, who also comments on how interest in making and studying egg collections has been historically common in the natural sciences, beginning with Aristotle (Thompson, 1992; Chapter XV). In addition to the overall shape of the egg, the internal structure of the eggshell provides evidence about the life history of the laying organism, as well as about the mechanisms of gas exchange that permits the growth of the developing embryo (Mikhailov, 1997, and references therein). For dinosaurs, the information provided by their fossilized eggs can shed light on taphonomical, ontogenetical, behavioural, and environmental issues helping to put together some of the pieces of the big puzzle of their biology (e.g., Carpenter, 1999; Horner, 2000).

Extensive sites around the globe have uncovered millions of eggshell parts, providing valuable information on the taphonomical processes involved in the fossilization conditions of their putative laying dinosaurs. Already in 1999, 237 sites around the world were reported (Carpenter, 1999) and many others have been discovered since, such as the Auca Mahuevo site in Patagonia, Argentina (Chiappe et al., 2004; for Spanish sites see, for example, Sanz et al., 1995; Sanz \& Moratalla, 1997; López-Martínez, 2000; López-Martínez et al., 2000). Tiny embryos amazingly preserved inside the egg have been instrumental in the analysis of late development and ontogeny, again whenever a positive match between embryo and adult fossil has been made (see, for example, Chiappe et al., 1998). Studies about the structure of whole fossilized nests have proved to be an invaluable source of data in portraying some dinosaurs as social and care giving reptiles (see reviews in Varrichio et al., 1999; Horner, 2000; Chiappe et al., 2005; Vila et al., 2010).

Studies on amniotic eggshells have shown that the pore system geometry determines the gas conductance of the eggshell according to metabolic requirements ( $\mathrm{Ar}$ et al., 1974; Rahn et al., 1987; Deeming, 2006; Jackson et al., 2008). The conductance value indicates the rate at which the amniotic egg exchanges gases during the incubation period. Gas exchange during egg incubation involves respiration and loss of water, which is known to be constant in modern birds (a $15 \%$ loss of water at the end of incubation independently of egg mass, incubation time, or weight; Rahn \& Ar, 1974; Rahn et al., 1979). The direct measurements on modern bird eggs show that conductance has a direct relationship with egg mass and eggshell permeability (pore canal system), which are also directly related to each other (Ar et al., 1974; Tullett \& Board, 1977;
Rahn et al., 1979; Deeming \& Thompson, 1991; Kern \& Ferguson, 1997). Studies on dinosaur eggshell can thus offer important information on palaeophysiology and nest palaeoenvironment.

In order to achieve an efficient gas exchange, the eggshell has a detailed 3-D microstructure, composed primarily by prisms and pores (Fig.1). Prisms are composed of calcite carbonate, which is deposited through a biomineralization process that involves active, protein directed, and deposition of calcium. Several proteins are involved in this process that forms crystalline structures of unique directionality (Lavelin et al., 2000).

Despite the many uses of computer techniques for threedimensional reconstruction of fossil material (for example, Franzosa, 2001a, 2001b; Witmer et al., 2003; DominguezAlonso et al., 2004), dinosaur eggshells have been rarely reconstructed. Only one study, to assess the integrity of a dinosaur eggshell as well as its hatching holes, made use of computed tomography to generate a reconstruction of a dinosaur eggshell (Jones et al., 1998). Recently, a whole clutch reconstruction of megaloolithid eggs has been reported using tomography (Vila et al., 2010), bringing new insights into dinosaur nest construction and behaviour. In contrast, the use of electron scanning microscopy is very common, showing the details of the external surface of the eggshell as well as the internal pores in sagittal views (e.g., López-Martínez, 2000; Jackson et al., 2002). Here, we carry out, for the first time, a three-dimensional computer reconstruction of the internal structures of a dinosaur eggshell. We have reconstructed a section of the eggshell of Megaloolithus siruguei, an eggshell that is unusual due to its complex internal pore network. The reconstruction shows the topological and geometrical details of the intricate organization of the pore system network, as well as the morphology of a prism.

\section{MATERIAL AND METHODS}

\subsection{Description of the eggshell}

Megaloolithus siruguei (Vianey-Liaud et al., 1994) from the Pyrenean Late Cretaceous is a particular dinosaur eggshell type having one of the Old World thickest eggshells. A clutch containing 7 eggs was found in situ in the grey marls at Biscarri (Late Cretaceous Tremp Formation, south central Pyrenees, Spain) (López-Martínez et al., 2000). Its eggshell has tubospherulitic architecture, made by large, conical and well-defined shell-units. Each of these units has a basal mammillary body in the internal eggshell surface, made by a rounded spherulite with symmetrically radiating calcite crystal fibres. From the mammillae outwards, a reversed cone-shaped bundle of 

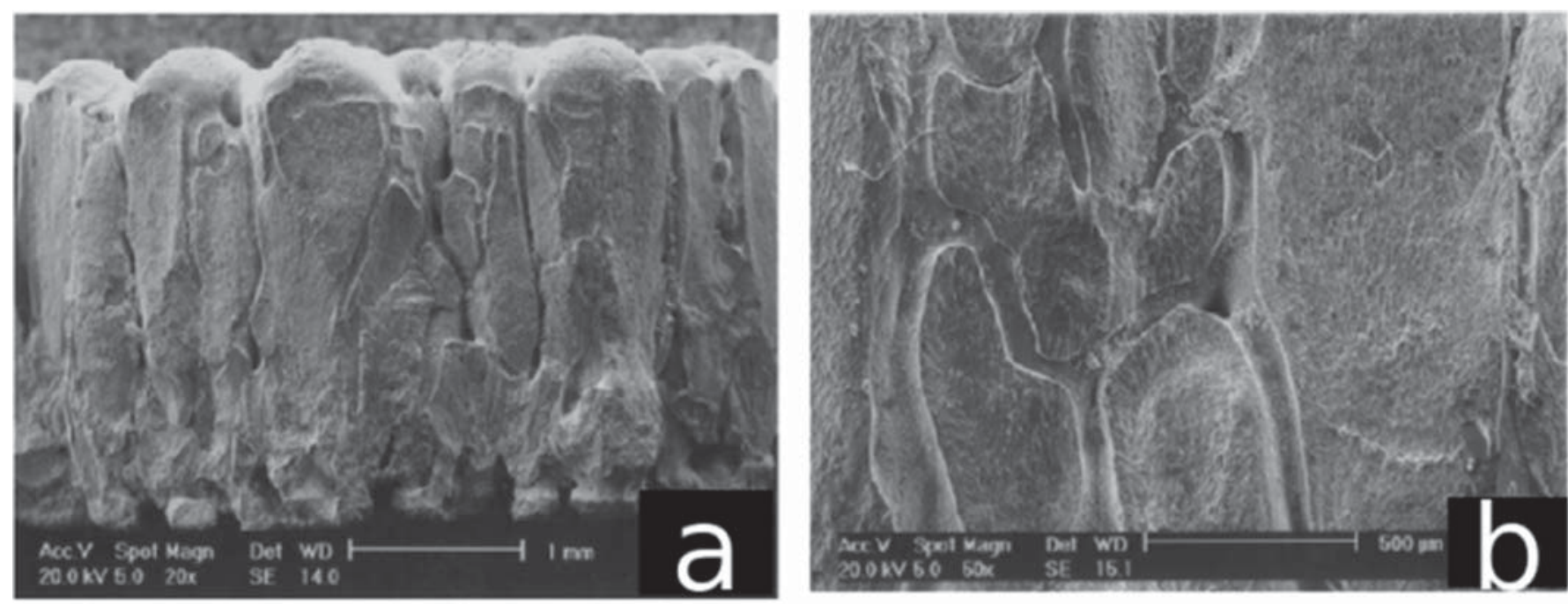

Figure 1. Scanning microscopy of a section of Megaloolithus siruguei eggshell in radial view. The intricacy of the pore system can be appreciated in the higher magnification image (b).

calcite crystal fibres grows and enlarges until it reaches the outer surface building a rounded cap (node), or is impeded by the surrounding shell units.

The shell thickness in M. siruguei varies between 2.1 to $3.5 \mathrm{~mm}$ ( $2.9 \mathrm{~mm}$ average), with a bimodal thickness distribution (López-Martínez et al., 2000). This value is correlated with the egg size, a relationship also seen in bird eggshells (Fig. 2). Thus, in birds, larger eggs have relatively lighter and fragile eggshells (Rahn \& Ar, 1974). The more permeable dinosaur eggshells with large egg sizes may have comparatively less strength than bird eggs of similar size. In spite of the wide range of egg masses, the average conductance and flux rates per pore have been shown to be constant in recent birds (Rahn et al., 1987).

The pore canals in $M$. siruguei are not just vertical (radial) or obliquely oriented as in other eggshells; rather, they show a unique network of long, regular, horizontal (tangential) canals connecting the vertical and oblique ones (Williams et al., 1984; Elez \& López-Martínez, 2000; López-Martínez et al., 2000). This special pore system has not been described in any other known eggshell type.

\subsection{Eggshell 3D reconstruction}

There are multiple methods for generating 3-D reconstructions based on invasive and non-invasive techniques. The invasive ones destroy the material that is being reconstructed, while the non-invasive ones preserve it altogether. The shape and size of the materials, as well as its composition determines the sort of technique to be employed. Fossil eggshells are unfortunately suitable for invasive methods, so that after the reconstruction the

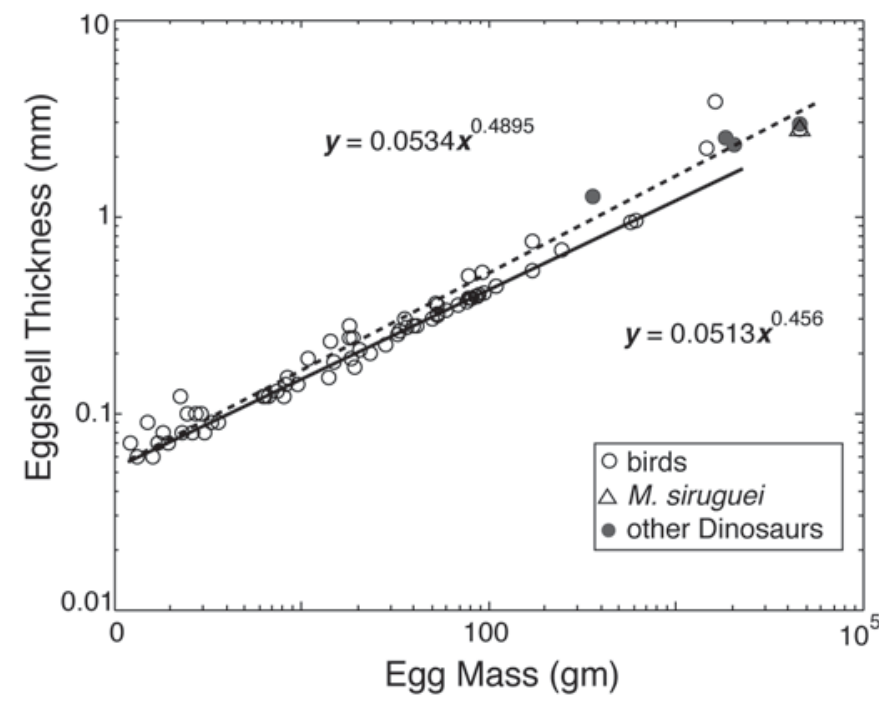

Figure 2. Relationship between eggshell thickness and egg mass in birds and some non-avian dinosaurs. The regression to a power function derived from the selected bird sample is compared with that from Rahn \& Ar (1974) based on a much larger bird sample. Data from Rahn \& Ar (1974), Seymour (1980), and López-Martínez et al. (2000).

original material is lost. A portion of the eggshells of a whole egg is a very thin flat patch that makes the usage of non-invasive techniques such as X-ray Computed Tomography (CT) very difficult. Newest high-resolution $\mathrm{X}$-ray CT is able to resolve details of a few tens of microns (a preliminary reconstruction made using X-ray CT proved to be of poor resolution). However, in the last years, the Digital Morphology project has generated hundreds of 
high-resolution 3-D reconstructions of other fossil material, as well as rocks and skeletal parts of extant organisms (Witmer et al., 2003; Dominguez-Alonso et al., 2004; see also http://www.digimorph.org/index.phtml). It is thus expected that, in the future, high-resolution micro CT scan will be extensively used to make very accurate $3-\mathrm{D}$ reconstructions of dinosaur eggshells.

We have applied the External Marker-Based Automatic Congruencing (EMAC, Streicher et al., 1997) 3-D reconstruction process, which offers a set of algorithms for the rapid and objective realignment of sections and a high degree of automation in the feature extraction (segmentation) and reconstruction processes. This method has been used extensively to generate 3-D reconstructions of high resolution of histological and embryonic sections, a series of specific macros were programmed in order to use it for the reconstruction of this eggshell. Thanks to these macros, the computer automatically performs all imageprocessing operations, such as section orientation and the extraction of the high-contrast morphological boundaries. This approach largely eliminates interactive processing by an operator and thus improves objectivity and time expense; the output of the EMAC processing is a stack of binary images of the selected signals and contours. Binary images of internal structures are obtained both by automating segmentation and manual tracing.
In the case of the dinosaur eggshell, the specimen must be destroyed by sequentially polishing the surface, thus obtaining serial sections. A problem with polishing techniques is that the $\mathrm{z}$-distance is sometimes inhomogeneous, so that when doing the reconstruction it was necessary to compensate for such a non-systematic error, as explained below.

We generated a complete 3-D reconstruction of a dinosaur eggshell patch of approximately $4 \mathrm{~mm}$ in diameter and $3 \mathrm{~mm}$ in depth. In order to make the reconstruction, sketches of serial sections were performed using a Wild M8 microscope at 50x. The average distance between sections was $0.1 \mathrm{~mm}$. The reconstruction is based on 37 sections from the external to the internal side of the eggshell. Of those 37 sections only 29 were used in the reconstruction. Due to an uneven distance between sections (spanning from 0.05 up to $2 \mathrm{~mm}$ ) it was necessary to average out these distances, introducing extra sections as repetitions of existing ones. Thus, the number of sections of the final reconstructed model was 45, including 29 real and 16 repetitions. The pores and the prisms were segmented directly from the images drawn from the microscope. The repetition of some of the sections preserves the overall configuration of pores and prisms at the expense of introducing minimum, non-significant morphological distortions. The algorithms to register and segment each

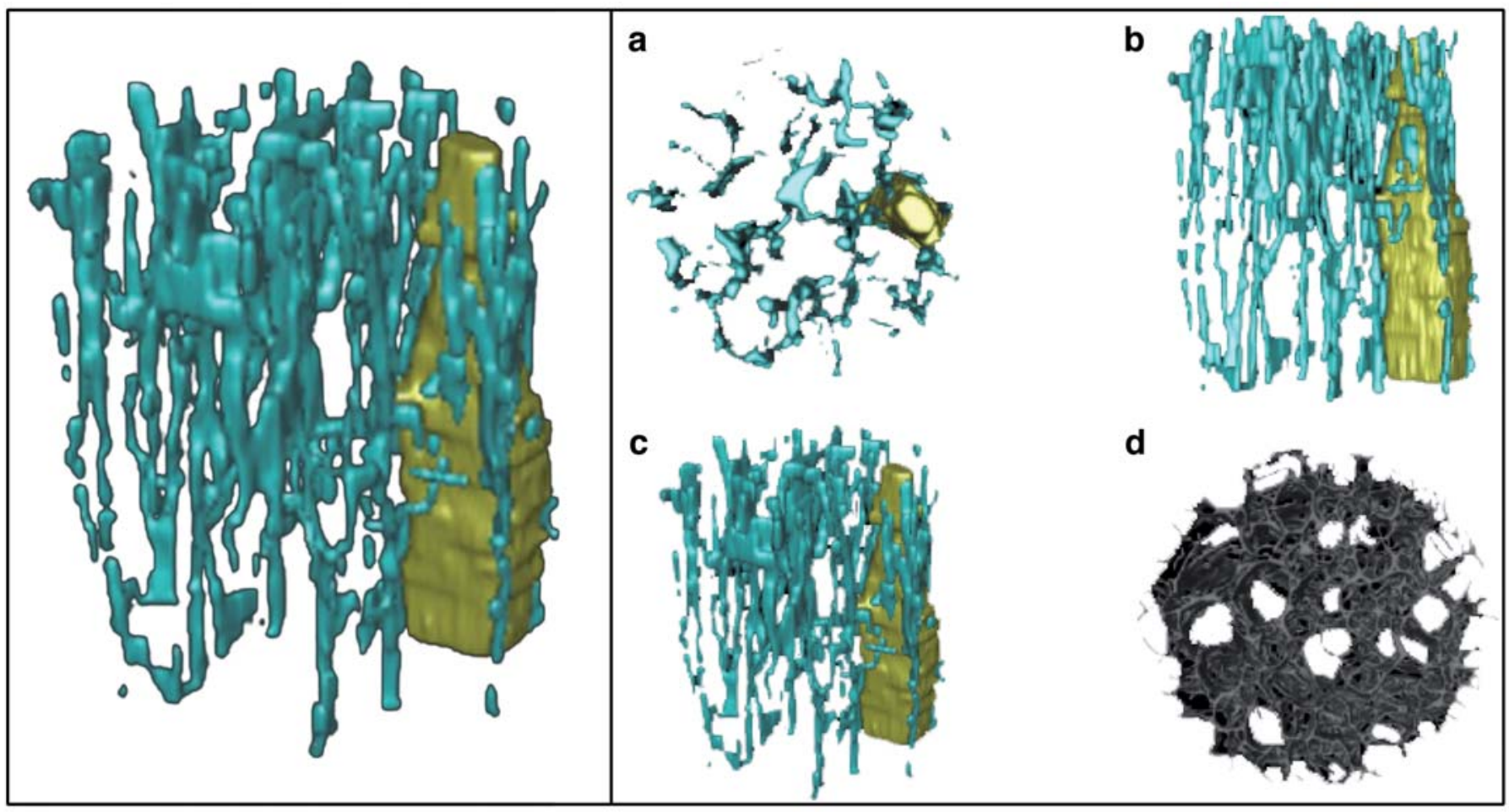

Figure 3. 3-D reconstruction of the pore systems of Megaloolithus siruguei. Note that, for clarity, only one crystal is shown in all views. Left. In dark grey/yellow, 3-D reconstruction of a crystal; in light grey/blue, the pore network. Right. a) Ventral view. b) Lateral view. c) Perspective. d) The interpore matrix, dorsal view. 
structure were made using the built-in macro language of the program NIHImage. Bitmap images were generated for each separate pore and prism element for each section.

The reconstruction was made on a Silicon Graphics Octane workstation, using the program Velocity. Pores and prisms were reconstructed separately and subsequently fused in a unique three-dimensional model (Fig. 3). Only one prism is shown, so that the whole network of pores can be better observed. From the Bitmap images it was possible to estimate quantitatively the average section for each pore and its volume capacity. An extrapolation was made in order to assess the total pore density and gas exchange capacity of the eggshell.

\section{RESULTS}

The 3-D reconstruction of this eggshell patch of Megaloolithus siruguei reveals with unprecedented detail a unique type of pore canal structure, composed of a horizontal network of regular canals connecting the vertical and oblique ones. The reconstruction of $M$. siruguei eggshell is shown in Figure 3. Direct extrapolation from the reconstructed segment shows that the total volume occupied by the pore channel corresponds to a $7.5 \%$ of the eggshell volume. In comparison, the pore canal system occupies a $13 \%$ of the shell volume in the ostrich, but only a $1.8 \%$ in the domestic chicken. The area of the pore sections increases as we move towards the internal part of the shell, with three statistically significant areas (see Fig. 4): external, sections $1-16$, mean $=8.68 \mathrm{~mm}^{2}$; medial, sections $17-23$, mean $=27.11 \mathrm{~mm}^{2}$; and internal, sections 24-29; mean $46.19 \mathrm{~mm}^{2}$. By examining the reconstructed model in different views, it is apparent that there is a hidden, non-connected porosity as well as several blind conducts in this eggshell (see Fig. 5 for a schematic representation).

We also tested Murray's law, which states that the cube of the radius of a parent vessel equals the sum of the cubes of the radii of the daughters. This type of branching pattern has been found in a large amount of organic vascular system, from arterial vessels to sponge channels (LaBarbera, 1995). According to the 3-D reconstructed branching pattern, this law does not hold for the pore system in this dinosaur eggshell.

\section{DISCUSSION}

The geometric arrangement of the calcite prisms determines the geometry and topology of the pores, i.e., the air passages that accommodate among them. The arrangement of these passages ranges from straight, isolated pores to more intricate networks, as in the case of the ostrich eggshell

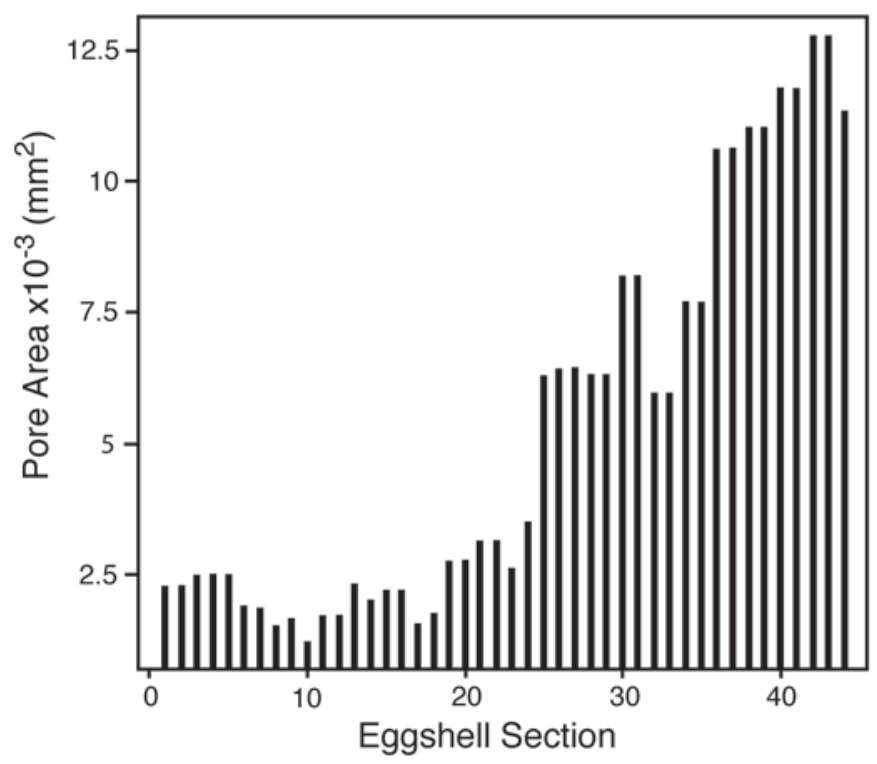

Figure 4. Variation of pore area in the sampled cylinder. The vertical axis denotes area in square $\mathrm{mm}$; the horizontal axis denotes number of sections, from external to the internal part of the shell. The area of the pore sections increases as we move towards the internal part of the shell. Pore area was calculated in the 29 eggshell sections (not including the repeated sections used to generate the 3-D reconstruction) along the internalexternal axis, where three regions are distinguished: external (section 1-16; mean $=8.68)$, medial (sections 17-23; mean $=27.11$ ), and internal (sections 24-29; mean $=46.19$ ). To test the existence of these three regions according to the pore area, a Kruskal-Wallis test was made using the SPSS 14.0 statistical pack, for a significance level $<0.05$ (Chi-Square $=21.895$; $p<0.0001)$.

or, as it is also the case with Megaloolithus siruguei. In modern birds and some dinosaurs, the pore ducts are usually straight, vertically oriented and independent one of each other. Other dinosaurs and rare large birds have pore canals with branching upward patterns and oblique orientation (Rahn et al., 1979; see also Figs 5 b-d).

This particular egg type was found in periaquatic palaeoenvironments, linked to ancient waterlogged, muddy soils that prevent burying the nest. As the Biscarri clutch was not buried, the high permeability of this eggshell impeding aerial nesting suggests a vegetation mound covering it (López-Martínez et al., 2000). These authors proposed that its peculiar pore system would have been an adaptive feature for reducing the suffocation effects if pores were obstructed by mud. However, recent experiments demonstrate that perfusion system in the chorioallantoic membrane assures the normal development of eggs even with a complete pore obstruction on half of the shell surface (Wagner-Amos \& Seymour, 2002). 
a

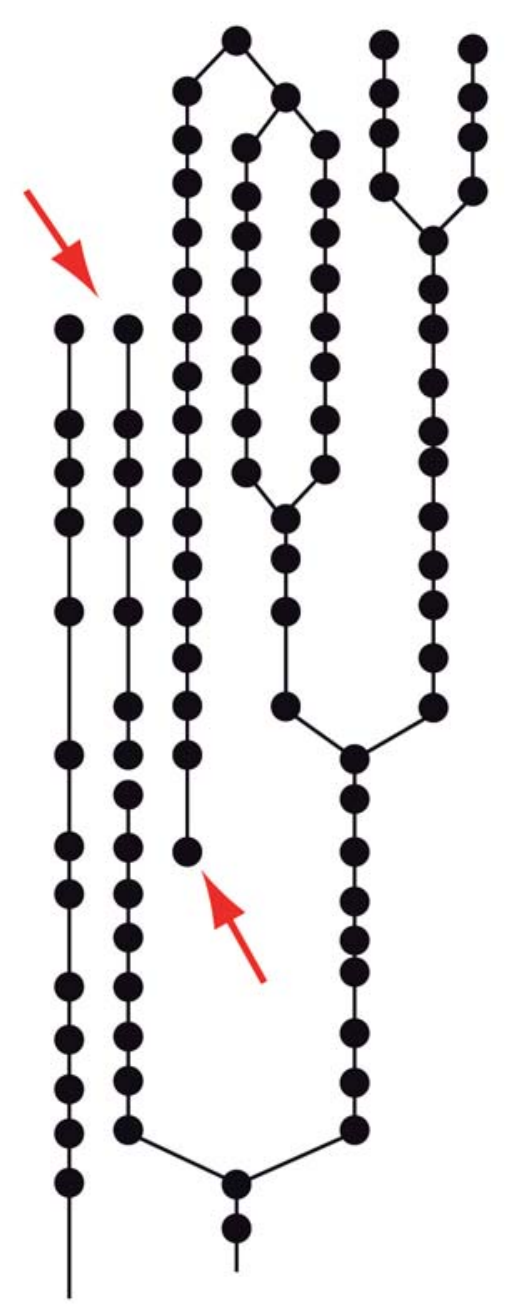

b

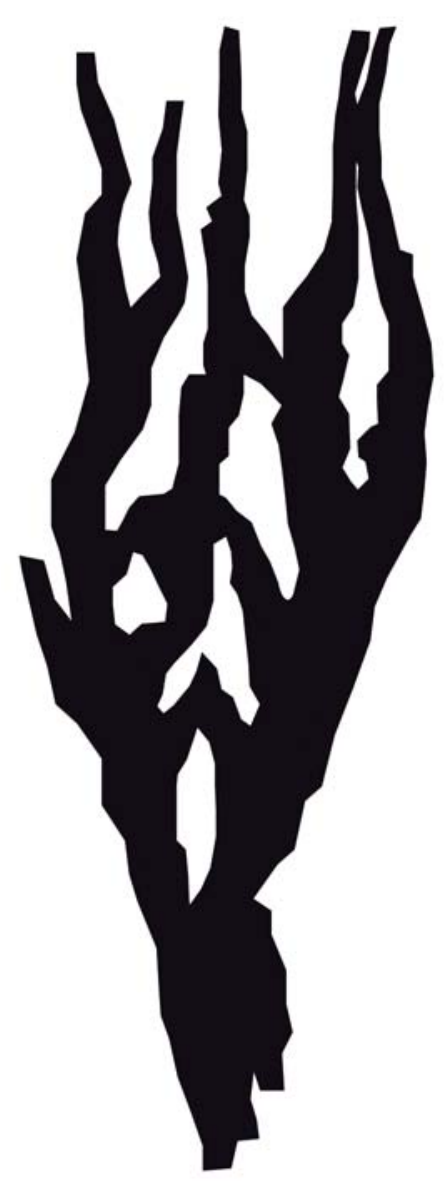

C

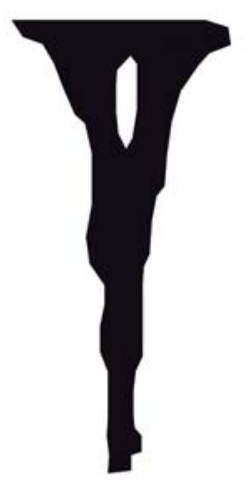

d

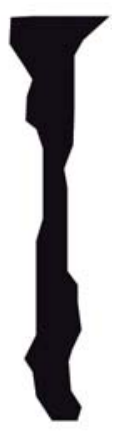

Figure 5. a) Topology of the pore system for a cylindrical volume of the reconstructed eggshell patch. b, c, and d) Topology of ostrich, rhea, and swan eggshell pores (after Rahn et al., 1979). The connectivity pattern of Megaloolithus siruguei shows an intricate internal network in which some pores are actually dead-ends (arrows), much as in the porosity pattern of the ostrich eggshell. Note the bifurcations and the horizontal and/or diagonal connections between vertical pores. Geometry is not preserved, only the topology, in order to highlight and clarify the intricacy of the internal network.

The intricate pore system pattern, as shown by the 3-D reconstruction for Megaloolithus siruguei, indicates a strategy towards a slower gas exchange rate by internal retention of fluids and a more fragile, lightly-built eggshell, opposite to the strategy of extant bird eggshells. This kind of pore canal arrangement would allow the retention of $\mathrm{CO}_{2}$ and water, which could generate a greenhouse effectlike inside the egg. This effect could protect the embryo from environmental heat changes, and it is compatible with the kind of nesting proposed for these eggs.

\section{ACKNOWLEDGMENTS}

Thanks to two very thorough anonymous reviewers for their accurate suggestions, as well as to the editor for his generous patience. We thank Miquel De Renzi and Angela D. Buscalioni for constructive feedback. We also thank the Morphology Group at the University of Vienna, were the computer reconstruction was carried out. Most of this work was done thanks to the never-ending enthusiasm and support of Nieves. Her departure makes us all scientific orphans. 


\section{REFERENCES}

Ar, A., Paganelli, C.V., Reeves, R.B., Greene, D.G. \& Rahn, H. 1974. The avian egg: water vapor conductance, shell thickness and functional pore area. The Condor, 76, 153-158.

Carpenter, K. 1999. Eggs, Nests, and Baby Dinosaurs. Indiana University Press, Bloomington.

Chiappe, L.M., Coria, R.A., Dingus, L., Jackson, F. \& Chinsamy, A. 1998. Sauropod dinosaur embryos from the Late Cretaceous of Patagonia. Nature, 396, 258-261.

Chiappe, L.M., Jackson, F., Coria, R.A. \& Dingus, L. 2005. Nesting titanosaurs from Auca Mahuevo and adjacent sites: understanding sauropod reproductive behavior and embryonic development. In: The Sauropods: Evolution and Paleobiology (eds. Curry-Rogers K.A. \& Wilson, J.A.). Berkeley and Los Angeles, University of California Press, 285-302.

Chiappe, L.M., Schmitt, J.G., Jackson, F.D., Garrido, A., Gingus, L. \& Grellet-Tinner, G. 2004. Nest structure for sauropods: sedimentary criteria for recognition of dinosaur nesting traces. Palaios, 19, 89-95.

Deeming, D.C. \& Thompson, M.B. 1991. Gas exchange across the reptilian eggshell. In: Egg Incubation: Its Effects on Embryonic Development in Birds and Reptiles (eds. Deeming, C. \& Ferguson, M.W.J.). Cambridge University Press, Cambridge, 277-284.

Deeming, D.C. 2006. Ultrastructural and functional morphology of eggshells supports the idea that dinosaur eggs were incubated buried in a substrate. Palaeontology, 49, 171-185.

Dominguez-Alonso, P., Milner, A.C., Ketcham, R.A., Cookson, M.J. \& Rowe, T.B. 2004. The avian nature of the brain and inner ear of Archaeopteryx. Nature, 430, 666-669.

Elez, J. \& López-Martínez, N. 2000. Interrelationships between growth of mineral phase and pore system in dinosaur eggshells. First International Symposium on Dinosaur Eggs and Babies, Abstract Book, p. 43-50.

Franzosa, J. 2001a. Dromaius novaehollandiae. Digital Morphology. Available at http://digimorph.org. Accessed November 21, 2007.

Franzosa, J. 2001b. Herrerasaurus ischigualastensis. Digital Morphology. http://digimorph.org. Accessed November 21, 2007.

Horner, J.R. 2000. Dinosaur reproduction and parenting. Annual Review of Earth and Planetary Sciences, 28, $19-45$.

Jackson, F.D., Schweitzer, M.H. \& Schmitt, J.G. 2002. Dinosaur eggshell study using scanning electron microscopy. Scanning, 24, 217-223.

Jackson, F.D., Varricchio, J., Jackson, R., Vila, B. \& Chiappe, L. 2008. Comparison of water-vapour conductance on a titanosaur egg from Argentina with a Megaloolithus siruguei from Spain. Paleobiology, 34, 229-246.
Jones, J.C., Greenberg, W. \& Ayers, M.S. 1998. Computed tomographic evaluation of dinosaur egg shell integrity. Veterinary Radiology and Ultrasound, 39, 133-136.

Kern, M.D. \& Ferguson, M.W.J. 1997. Gas permeability of American alligator eggs and its anatomical basis. Physiological Zoology, 70, 530-546.

LaBarbera, M. 1995. The design of fluid transport systems: a comparative perspective. In: Flow-Dependent Regulation of Vascular Function (eds. Bevan, J.A., Kaley, G. \& Rubanyi, G.M.). Oxford University Press, New York, 3-27.

Lavelin, I., Meiri, N. \& Pines, M. 2000. New insight in eggshell formation. Poultry Sciences, 79, 1014-1017.

López-Martínez, N. 2000. Eggshell sites from the CretaceousTertiary transition in South-Central Pyrenees (Spain). First International Symposium on Dinosaur Eggs and Babies, Abstract Book, p. 95-115.

López-Martínez, N., Moratalla, J.J. \& Sanz, J.L. 2000. Dinosaurs nesting on tidal flats. Palaeogeography, Palaeoclimatology, Palaeoecology, 160, 153-163.

Mikhailov, K.E. 1997. Eggs, eggshells, and nests. In: Encyclopaedia of Dinosaurs (eds. Currie, P.J. \& Padian, K.). Academic Press, Amsterdam, 205-209.

Rahn, H. \& Ar, A. 1974. The avian egg: Incubation time, water loss and nest humidity. Condor, 76, 147-152.

Rahn, H., Ar, A. \& Paganelli, C.V. 1979. How bird eggs breathe. Scientific American, 240, 46-55.

Rahn, H., Ar, A. \& Paganelli, C.V. 1987. Pores and gas exchange of avian eggs: a review. Journal of Experimental Zoology, 1, 165-172.

Sanz, J.L. \& Moratalla, J.J. 1997. Bastús nesting site. In: Encyclopedia of Dinosaurs (eds. Currie, P.J. \& Padian, K.). Academic Press, Amsterdam, 42.

Sanz, J.L., Moratalla, J.J., Díaz-Molina, M., López-Martínez, N., Kälin, O. \& Vianey-Liaud, M. 1995. Dinosaur nests at the sea shore. Nature, 376, 731-732.

Seymour, R.S. 1980. Dinosaur eggs: the relationships between gas conductance through the shell, water loss during incubation and clutch size. Mémoires de la Société Géologique de France, 139, 177-184.

Streicher, J., Weninger, W.J. \& Müller, G.B. 1997. External marker-based automatic congruencing: a new method of 3D reconstruction from serial sections. Anatomical Record, 248, 583-602.

Thompson, D.W. 1992. On Growth and Form. Dover, reprinted from 1942 2nd ed. (1st ed., 1917).

Tullett, S.G. \& Board, R.G. 1977. Determinants of avian eggshell porosity. Journal of Zoology, 183, 203-211.

Varricchio, D.J., Jackson, F. \& Trueman, C.N. 1999. A nesting trace with eggs for the Cretaceous theropod dinosaur Troodon formosus. Journal of Vertebrate Paleontology, 19, 91-100.

Vianey-Liaud, M., Mallan, P., Buscail, O. \& Montgelard, C. 1994. Review of French dinosaur eggshells: morphology, structure, mineral, and organic composition. In: Dinosaur Eggs and Babies (eds. Carpenter, K., Hirsch, K.F. \& Horner, J.R.). Cambridge University Press, Cambridge, 151-183. 
Vila, B., Jackson, F.D., Fortuny, J., Sellés, A.G. \& Galobart, À. 2010. 3-D modelling of megaloolithid clutches: Insights about nest construction and dinosaur behaviour. PLoS ONE, 5, e10362.

Wagner-Amos, K. \& Seymour, R.S. 2002. Effect of regional changes to shell conductance on oxygen consumption and growth of chicken embryos. Respiration Physiology, 129, 385-395.
Williams, D.L.G., Seymour, R.S. \& Kerourio, P. 1984. Structure of fossil dinosaur eggshell from the Aix basin, France. Palaeogeography, Palaeoclimatology, Palaeoecology, 45, 23-38.

Witmer, L.M., Chatterjee, S., Franzosa, J. \& Rowe, T. 2003. Neuroanatomy of flying reptiles and implications for flight, posture and behaviour. Nature, 425, 950-953. 